Eur J Clin Chem Clin Biochem

1995; 33:491-496

(C) 1995 Walter de Gruyter \& Co.

Berlin · New York

\title{
Time Changes of Creatine Kinase and Creatine Kinase-MB Isoenzyme versus Discrimination Values in the Diagnosis of Acute Myocardial Infarction: What is the Optimal Method for Displaying the Data?
}

\author{
By John A. Lott, John W. Heinz and Kathleen A. Reger \\ Department of Pathology, The Ohio State University Medical Center, Columbus, OH, USA
}

(Received July 13, 1994/May 10, 1995)

Summary: We wanted to determine the optimal method for displaying data for the clinical evaluation of patients with possible acute myocardial infarction. Our primary question was, are the time changes (slopes) of the enzyme tests better predictors of disease than the discrimination values, i.e., the cut-off points? We studied 152 patients with and 114 without a diagnosis of acute myocardial infarction in their medical records. For patients with acute myocardial infarction, we found the most discriminating tests, in decreasing order of the area of the ROC curves, to be the creatine kinase-MB slope at 0 to 12 hours, the creatine kinase-MB slope at 12 to 24 hours, the creatine kinase-MB values between 12 and 24 hours, and the creatine kinase-MB values between 0 and 12 hours. Decreasing values of creatine kinase-MB in the first tests after admission were only slightly less discriminating than increasing ones. At 12 to 24 hours after admission, the total creatine kinase as a value or slope, or the "relative index" (a ratio of the creatine kinase-MB in $\mu \mathrm{g} / \mathrm{l}$ [times 100] to the total creatine kinase) as a value or slope were inferior to creatine kinase-MB presentations. From the data for 44 patients with acute myocardial infarction and a known time of onset of symptoms, we were able to estimate an approximate onset time in patients where this was not available. We recommend that changes in the creatine kinase-MB concentration with time and the values themselves should be displayed in all patients with suspected acute myocardial infarction, and that at least three specimens should be collected in the 24-h period after admission. Analog representation of the data along with calculated slopes facilitate the identification of patients with possible acute myocardial infarction. The creatine-kinase-MB test has clear limitations: several conditions have values or slopes that suggested infarction but are really something else.

\section{Introduction}

In many patients with chest pain, the diagnosis of acute myocardial infarction cannot be made at the first contact in the Emergency Department. Diagnosing or excluding acute myocardial infarction in a patient with chest discomfort is a difficult problem, moreover, for "most patients, neither the history nor laboratory tests can be used to exclude the possibility of infarction" (1). The electrocardiogram, although specific, has a sensitivity of only $68 \%$ to $73 \%(2,3)$. Furthermore, the best, widely available blood test for acute myocardial infarction, creatine kinase-MB isoenzyme (creatine kinase, EC 2.7.3.2), has a sensitivity of only $34 \%$ when the patient is seen early on (3). Clearly, premature discharges from the Emer- gency Department, based on a non-diagnostic ECG or a normal creatine kinase-MB could be disastrous for the patient. Bernstein et al. (4), and Collinson et al. (5), stressed the importance of following the changes in the serum creatine kinase or creatine kinase-MB for about 12 hours in attempting a diagnosis of acute myocardial infarction. The same strategy can be used in most patients to identify those were acute myocardial infarction is unlikely. Leung et al. (6) found that discrimination values or cut-off points were superior to time changes of the values in categorizing patients with possible acute myocardial infarction; thus there is some disagreement in the literature on how best to use the data. Of course, 
the laboratory data are only part of the information used in the decision to admit or discharge a patient, and overreliance on biochemical markers can lead to misdiagnoses (7).

In view of the controversy in the literature, our first goal was to determine how the data are best reported or displayed for all patients coming to the Emergency Department with chest pain where acute myocardial infarction is part of the differential diagnosis. We wanted to determine which of the following displays discriminated best between patients with and without a diagnosis of acute myocardial infarction: changes with time (slopes) or optimized decision point estimates for creatine kinase, creatine kinase- $\mathrm{MB}$, or a relative index. The relative index is the ratio of the creatine kinase-MB in $\mu \mathrm{g} / 1$ (times 100 ) to the total creatine kinase. Another goal was to determine the ranges of values of the above slopes and tests in patients with acute myocardial infarction. Finally, we sought an estimate of the proportion of patients who delayed coming to the Emergency Department, defined here as those having decreasing creatine kinase-MB values with time: from the first blood specimen on.

\section{Materials and Methods}

Patient Group A

Patients with suspected acute myocardial infarction

We included all patients coming to our Emergency Department with chest pain during a recent six-month period who had a presumptive diagnosis of possible acute myocardial infarction and who had at least three creatine kinase and creatine kinase-MB assays performed in the first 24 hours after admission. A total of 266 patients were retained in the study. Blood specimens were collected on admission and again at approximately eight and sixteen hours later to give three collections in 24 hours. The final diagnoses were obtained from the patients' medical records. The usual criteria for diagnosing acute myocardial infarction and what were used at The Ohio State University Hospitals are described elsewhere (6). We excluded in the above patients having thoracic surgery of any kind, balloon angioplasty, atherectomy, and any other type of invasive cardiology within the first 24 hours after admission. We also excluded from this group those with dilated or ischemic cardiomyopathy, chest trauma or chest contusions, and cocaine cardiomyopathy. The time of onset of symptoms was obtained from the chart. We accepted as valid a stated time of day for the onset but considered invalid for our purposes statements like "in the morning", "sometime in the evening" and so on.

Patient Group B

Patients with dilated or ischemic myopathies or "cocaine heart"

In addition to the patients listed above, we reviewed data from 13 patients with dilated or ischemic myopathies and three patients with "cocaine heart." We wanted to test our scheme of analyzing the data in patients with heart disease but not acute myocardial infarction.

\section{Methods}

Creatine kinase assays were performed on a Kodak Ektachem 700 $\mathrm{XR}$ instrument at $37^{\circ} \mathrm{C}$ (Eastman Kodak, Rochester, NY 14650,
USA). Creatine kinase-MB values, as the mass of protein, were determined at $37^{\circ} \mathrm{C}$ by the chemiluminescent, double-antibody immunoassay on a Corning ACS 180 analyzer (Ciba Corning Diagnostics Corp., Medfield, MA 02052, USA); the performance of both tests followed the manufacturer's instructions exactly. All tests were performed on a STAT basis with a turn-around time of one hour or less on a 24-hour-per-day basis. Between-day proficiency data for creatine kinase and creatine kinase-MB obtained in our routine clinical chemistry laboratory are shown in table 1.

\section{Reference values}

Our upper reference intervals for creatine kinase are $232 \mathrm{U} / \mathrm{l}$ for men and $212 \mathrm{U} / \mathrm{l}$ for women. For creatine kinase-MB and the relative index, our upper reference limit are $7 \mu \mathrm{g} / \mathrm{l}$ and $<1.0$. respectively, for both genders. The $90 \%$ sensitivity cut-off limits are shown in table 2.

\section{Data analysis}

The changes in concentrations (or activities) of the analytes per hour were determined exactly as described elsewhere (5). A patient was assigned to the "negative slope group" if the creatine kinaseMB concentration in the second specimen was less than that in the first specimen obtained in the Emergency Department. The slope calculated for the first time period ( 0 to 12 hours) included the specimen collected on admission plus the next one, being typically obtained 8 to 12 hours later. For the second time period (12 to 24 hours), the results from the specimens collected at 8 to 12 hours after admission and that collected at about 16 to 24 hours post admission were used. We chose the two 12 -hour cycles post-admission based on the test ordering habits at our institution and the findings of Puleo et al. (8), who found that obtaining maximum sensitivities for creatine kinase-MB requires that about 12 hours must elapse between specimen collections.

\section{Results and Discussion}

\section{Diagnoses}

In Patient group A, a total of 152 patients had a diagnosis of acute myocardial infarction in their medical records; of these, 74 had increasing then decreasing creatine kinase-MB values, and 78 had only decreasing creatine kinase-MB values during the first eight to 12 hours post admission; the latter is a much larger proportion than the 5 of 151 individuals with confirmed acute myocardial infarction found by others (6). These authors calculated the time from the onset of symptoms and used 7 to 12 hours and 13 to 18 hours as their time intervals,

Tab. 1 Between-day reproducibility of creatine kinașe and creatine kinase-MB assays ${ }^{\mathrm{a}}$

\begin{tabular}{llcc}
\hline Test & Number & Mean & SD \\
\hline Creatine kinase, & 97 & 181.2 & 7.34 \\
U/1 & 95 & 1111 & 21.4 \\
& & & \\
Creatine kinase-MB, & 118 & 8.78 & 0.49 \\
$\mu \mathrm{g} / \mathrm{l}$ & 119 & 88.3 & 7.71 \\
\hline
\end{tabular}

a Creatine kinase assayed on Kodak Ektachem $700 \mathrm{XR}$ and creatine kinase-MB on Corning ACS 180 Analyzer. 
Tab. 2 Ninety percent sensitivity cut-off values for slopes and values of the tests

\begin{tabular}{lllllll}
\hline & $\begin{array}{l}\text { Creatine } \\
\text { kinase } \\
0-12 \text { hours }\end{array}$ & $\begin{array}{l}\text { Creatine } \\
\text { kinase } \\
12-24 \text { hours }\end{array}$ & $\begin{array}{l}\text { Creatine } \\
\text { kinase-MB } \\
0-12 \text { hours }\end{array}$ & $\begin{array}{l}\text { Creatine } \\
\text { kinase-MB } \\
12-24 \text { hours }\end{array}$ & $\begin{array}{l}\text { Relative } \\
\text { index } \\
0-12 \text { hours }\end{array}$ & $\begin{array}{l}\text { Relative } \\
\text { index } \\
12-24 \text { hours }\end{array}$ \\
\hline $\begin{array}{l}\text { Positive slopes } \\
\text { for creatine kinase-MB }\end{array}$ & 5.11 & 2.00 & 0.38 & 0.41 & 0.070 & 0.040 \\
$\begin{array}{l}\text { Negative slopes } \\
\text { for creatine kinase-MB }\end{array}$ & 2.56 & 3.40 & 0.27 & 0.30 & 0.040 & 0.050 \\
\hline
\end{tabular}

\begin{tabular}{lllllll}
\hline & $\begin{array}{l}\text { Creatine } \\
\text { kinase } \\
0 \text { hours }\end{array}$ & $\begin{array}{l}\text { Creatine } \\
\text { kinase } \\
8-12 \text { hours } \\
\text { later }\end{array}$ & $\begin{array}{l}\text { Creatine } \\
\text { kinase-MB } \\
0 \text { hours }\end{array}$ & $\begin{array}{l}\text { Creatine } \\
\text { kinase-MB } \\
8-12 \text { hours } \\
\text { later }\end{array}$ & $\begin{array}{l}\text { Relative } \\
\text { index } \\
0 \text { hours }\end{array}$ & $\begin{array}{l}\text { Relative } \\
\text { index } \\
8-12 \text { hours } \\
\text { later }\end{array}$ \\
\hline Test value & 134 & 165 & 7.30 & 11.6 & 2.96 & 2.75 \\
\hline
\end{tabular}

a Slope of first two specimens for creatine kinase-MB, i.e., at admission and at 8 to 12 hours later.

Data for group A patients only. "0" hours is time of first test in Emergency Department.

Tab. 3 Relationship of enzyme slopes and delay to first test

\begin{tabular}{llllr}
\hline $\begin{array}{l}\text { Hours from onset } \\
\text { to admission }\end{array}$ & $\begin{array}{l}\text { Total number } \\
\text { of patients }\end{array}$ & $\begin{array}{l}\text { Number (\%) } \\
\text { with positive } \\
\text { creatine kinase slope }\end{array}$ & $\begin{array}{l}\text { Number (\%) } \\
\text { with positive } \\
\text { creatine kinase-MB slope }\end{array}$ & $\begin{array}{l}\text { Number (\%) } \\
\text { with positive } \\
\text { relative index slope }^{\mathbf{a}}\end{array}$ \\
\hline 1 to 6 & 14 & $14(100)$ & $13(93)$ & $11(79)$ \\
1 to 12 & 24 & $20(83)$ & $17(71)$ & $17(71)$ \\
1 to 24 & 36 & $26(72)$ & $20(56)$ & $20(56)$ \\
$>24$ & 8 & $2(25)$ & $3(38)$ & $3(38)$ \\
\hline
\end{tabular}

a A positive slope occurs if the activity of the second specimen collected eight to 12 hours after admission has a higher activity

than the first specimen drawn on admission. Data are from the 44 patients with known time of onset of symptoms. hence their and our study are not directly comparable. We found unambiguous statements in the medical records of the time of onset of symptoms in 44 of our 152 patients.

In group $\mathrm{A}$ with acute myocardial infarction, there were 110 men, mean age $58.4 \pm 11.7$ (SD) years, and 42 women, mean age $62.9 \pm 14.4(\mathrm{SD})$ years. 114 patients did not have a diagnosis of acute myocardial infarction in their records; in some, "questionable" acute myocardial infarction, "intermediate coronary syndrome", "positive subendocardial event" or "possible acute ischemia" were present in their medical record. We elected to call the time of the first blood specimen as time zero for all cases with acute myocardial infarction whether the onset time was known or not. About $71 \%$ of our patients with acute myocardial infarction has vague or unknown onset times.

We recognize that patients with a significantly delayed admission (e. g., $>12$ hours after onset) may not show the typical increasing then decreasing creatine kinase$\mathrm{MB}$ values; however, care givers must deal with the patients as they arrive, and we have no control on how long individuals wait to seek aid after the onset of symptoms. Negative initital slopes for the enzymes must also be used in decision making where possible and be displayed to indicate this. Such slopes allow the approximate separation of patients into early or late arrivals in the Emergency Department after onset of symptoms. In table 3, we show the number of patients with a positive slope in the specimen drawn on admission and the next one drawn eight to 12 hours later for creatine kinase, creatine kinase-MB, and the relative index. Our data suggest that a delay in seeking aid is likely to result in a negative slope for the indicated tests. In a patient with an unknown onset time, a negative slope suggests an onset time of $>6$ hours prior to admission.

\section{Data ranges}

In the group A patients with acute myocardial infarction tested at 12 to 24 hours after admission, 120 had creatine kinases of $>250 \mathrm{U} / \mathrm{l}, 78 \mathrm{had}>500 \mathrm{U} / \mathrm{l}$, and $45 \mathrm{had}$ $>1000 \mathrm{U} / \mathrm{l}$; for each category at 0 to 12 hours, the corresponding number of patients were about $20 \%$ smaller. In the non-infarct group at 12 to 24 hours, only 8 of the 
114 patients had creatine kinases $>500 \mathrm{U} / \mathrm{l}$. We recommend that the analog data displays use the logs of the values or slopes, and that the $\vec{y}$-axis be expandable to cover the observed values.

Some patients with acute myocardial infarction and increasing creatine kinase-MB values showed huge changes of the creatine kinase activity per hour in the first 24 hours: 23 had changes of $>100 \mathrm{U} / \mathrm{h}$ in the first 12 hours; 10 had like changes in the second 12 hours. Four to five percent of the non-acute myocardial infarction patients showed slopes of this magnitude at either time interval. Any display scheme must consider such possible changes. At 12 to 24 hours, 87 of the 152 patients with diagnosed acute myocardial infarction had creatine kinase-MB values $>50 \mu \mathrm{g} / \mathrm{l}, 58 \mathrm{had}>100 \mu \mathrm{g} / \mathrm{l}$ and $23 \mathrm{had}>300 \mu \mathrm{g} / \mathrm{l}$. For the 0 to 12 hour period, the corresponding values are 73 patients with a creatine kinase-MB $>50 \mu \mathrm{g} / \mathrm{l}, 45$ with $>100 \mu \mathrm{g} / \mathrm{l}$, and 15 with $>300 \mu \mathrm{g} / \mathrm{l}$. Like creatine kinase, the creatine kinase$\mathrm{MB}$ values were higher in the second 12-hour period after admission. During the 12 to 24-hour period, the change in creatine kinase-MB was $>20 \mu \mathrm{g} / \mathrm{l} \cdot \mathrm{h}$ in 98 , and $>40 \mu \mathrm{g} / \mathrm{l} \cdot \mathrm{h}$ in 82 of these 152 patients; the proportion of patients with such slopes in the first 12 hours was slightly smaller.

\section{Receiver operating characteristics curves}

The use of ROC curves to judge test accuracy is described in detail elsewhere (9). The ROC curves for the group A patients are here as figures $1 \mathrm{a}, 1 \mathrm{~b}$, and $1 \mathrm{c}$; the areas under the curves, $\mathrm{SDs}$, and $p$ values are given in table 4 . The area under the ROC curve for a positive creatine kinase-MB slope within the first 12 hours is significantly larger than the same test as a single value within the same time interval. For the same comparisons at 12 to 24 hours, there is no significant difference. The slope of or the total creatine kinase and the slope of or total relative index give essentially the same information in all the groups; we found little advantage in calculating the relative index.

Patients in group B with conditions mimicking acute myocardial infarction

Nearly all the patients having invasive cardiology had both abnormal creatine kinase-MB values and slopes within the first 24 hours after the procedure; an early diagnosis of acute myocardial infarction in this group is problematic. An additional 13 patients with dilated or ischemic cardiomyopathy all had creatine kinase-MB values of $>7 \mu \mathrm{g} / \mathrm{l}$ and values above the $90 \%$ sensitivity cut-off limit for creatine kinase-MB. The creatine kinase-MB slopes were $>0.38 \mu \mathrm{g} / \mathrm{l} \cdot \mathrm{h}$ in 11 of the 13
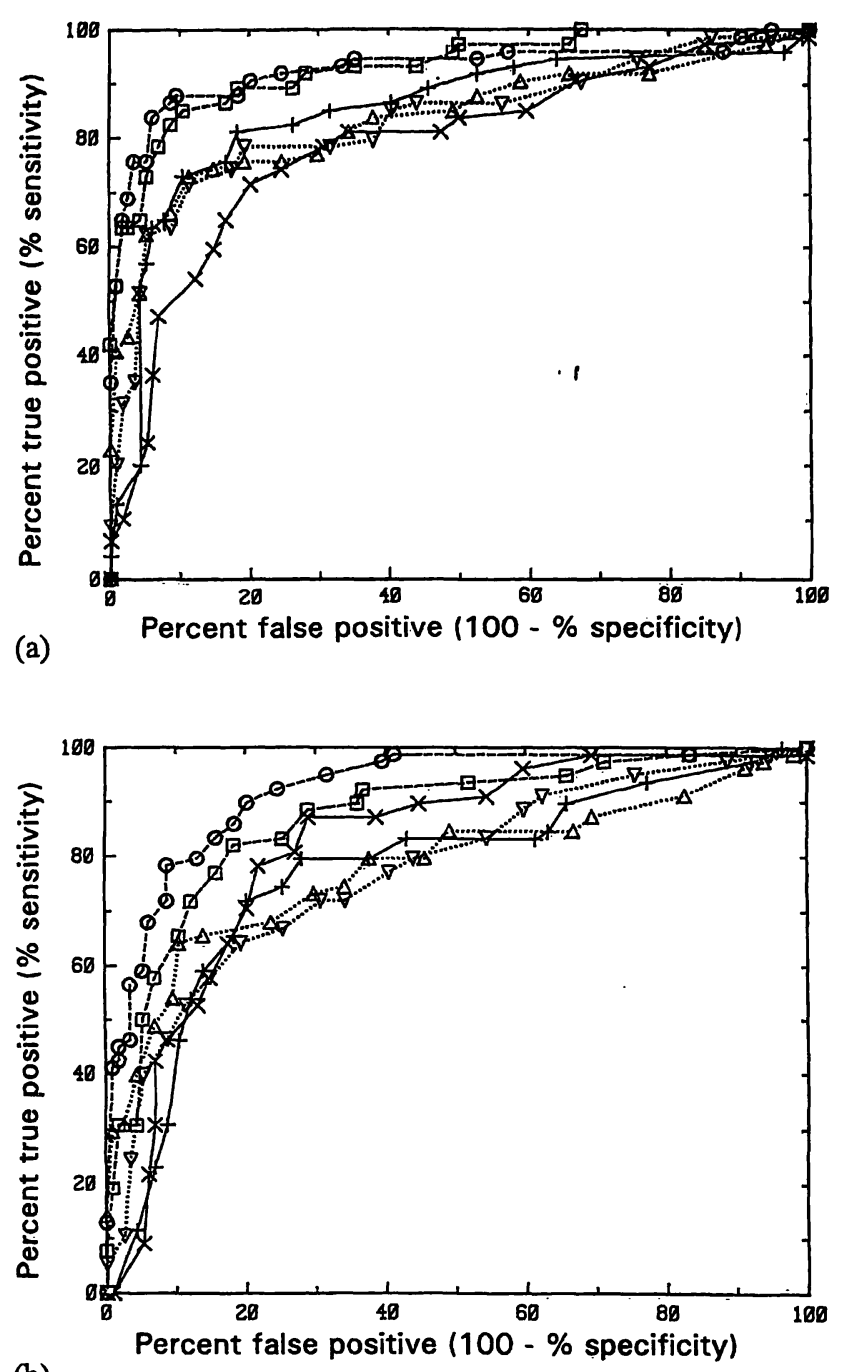

(b)

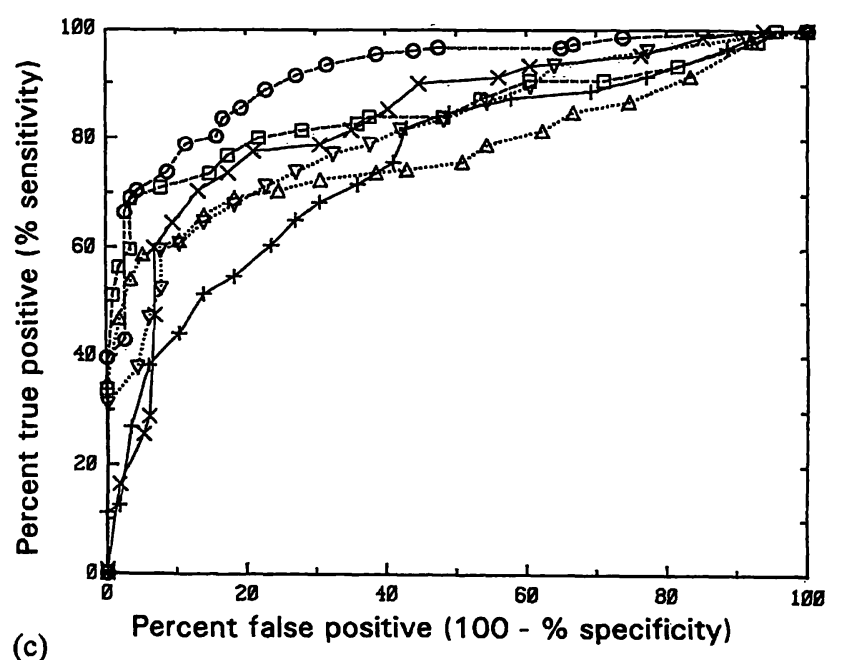

Fig. 1 Receiver operating characteristics plot

a) for 74 patients with acute myocardial infarction and a positive slope of creatine kinase-MB in the first 12 hours:

+ and solid line, creatine kinase slope at 0 to 12 hours;

$X$ and solid line; creatine kinase slope at 12 to 24 hours;

$\square$ and dashed line, creatine kinase-MB slope at 0 to 12 hours;

$O$ and dashed line, creatine kinase-MB slope at 12 to 24 hours;

$\Delta$ and dotted line, relative index slope at 0 to 12 hours;

$\nabla$ and dotted line, relative index slope at 12 to 24 hours.

b) for 78 patients with acute myocardial infarction and a negative slope of creatine kinase-MB in the first 12 hours.

c) for value of analyte rather than slope. Data shown for all patients with acute myocardial infarction. 
Tab. 4 Areas under the ROC curves (SD)

\begin{tabular}{|c|c|c|c|c|c|c|}
\hline & $\begin{array}{l}\text { Creatine } \\
\text { kinase } \\
0-12 \text { hours }\end{array}$ & $\begin{array}{l}\text { Creatine } \\
\text { kinase } \\
12-24 \text { hours }\end{array}$ & $\begin{array}{l}\text { Creatine } \\
\text { kinase-MB } \\
0-12 \text { hours }\end{array}$ & $\begin{array}{l}\text { Creatine } \\
\text { kinase-MB } \\
12-24 \text { hours }\end{array}$ & $\begin{array}{l}\text { Relative } \\
\text { index } \\
0-12 \text { hours }\end{array}$ & $\begin{array}{l}\text { Relative } \\
\text { index } \\
12-24 \text { hours }\end{array}$ \\
\hline $\begin{array}{l}\text { Positive intitial } \\
\text { creatine kinase-MB } \\
\text { slope } \\
\text { (See fig. 1a) }\end{array}$ & $\begin{array}{l}0.835 \\
(0.031)^{a, b}\end{array}$ & $0.776(0.035)^{b}$ & $0.931(0.019)$ & $\begin{array}{l}0.927(0.021) \\
\text { NS }\end{array}$ & $0.834(0.033)^{b}$ & $0.835(0.031)^{b}$ \\
\hline $\begin{array}{l}\text { Negative initial } \\
\text { creatine kinase-MB } \\
\text { slope } \\
\text { (See fig. lb) }\end{array}$ & $\begin{array}{l}0.765 \\
(0.035)^{c}\end{array}$ & $0.804(0.031)^{c}$ & $0.865(0.027)$ & $\begin{array}{l}0.922(0.019) \\
\text { NS }\end{array}$ & $0.781(0.035)^{\mathrm{c}}$ & $0.771(0.034)^{\mathrm{c}}$ \\
\hline $\begin{array}{l}\text { Values of analytes } \\
\text { (See fig. 1c) }\end{array}$ & $\begin{array}{l}0.758 \\
(0.029)^{d}\end{array}$ & $0.830(0.025)^{d}$ & $\begin{array}{l}0.859(0.023) \\
\text { NS }\end{array}$ & $0.918(0.017)$ & $0.797(0.027)^{d}$ & $0.817(0.025)^{d}$ \\
\hline
\end{tabular}

a The figures (and SD) are the areas under the ROC curves shown in the indicated figures and were calculated using the LABORCl software.

${ }^{b} \mathrm{p}<0.01$ as compared to creatine kinase-MB slope at 0 to 12 hours.

patients; two had values below the $90 \%$ sensitivity cutoff limits for the slope, a small advantage. For the three patients with cocaine poisoning and likely heart injury, the creatine kinase-MB values were abnormal in 2 of 3 , whereas the slopes at 0 to 12 hours were all below the $90 \%$ sensitivity cut-off.

\section{Conclusions}

We conclude from our data that estimates of the change in creatine kinase-MB per hour should be made for all patients with suspected acute myocardial infarction, and the analog displays of the slopes and values should be made available. Furthermore, slope estimates for creatine kinase-MB should be displayed for at least the first 24 hours after admission. Use of cut-off values for single test results is less effective than the use of slopes in the diagnosis of suspected acute myocardial infarction in the first 12 hours after admission.

The areas under the ROC curves can be used to determine the accuracy of a test over the entire range of sen- c $\mathrm{p}<0.01$ as compared to creatine kinase-MB slope at 12 to 24 hours.

${ }^{d} \mathrm{p}<0.01$ as compared to creatine kinase-MB value at 12 to 24 hours.

NS (not significant); $p>0.05$ vs. adjacent creatine kinase-MB data in table.

sitivity and specificity pairs (9). With this measure, creatine kinase-MB slopes at 0 to 12 hours post-admission are the most accurate. Testing patients with suspected acute myocardial infarction for an abnormal creatine kinase-MB is the current standard of care. Collinson et al. (10) showed that the creatine kinase-MB test had greater sensitivity than troponin $T$, although the latter has the advantage of remaining abnormal for a longer period of time (11). How the data are displayed may very well determine how the data are used. We recommend that slopes and the ordinary test results be displayed on computer terminals or printed to facilitate decision making in patients with suspected acute myocardial infarction.

\section{Acknowledgements}

We thank the staff of the Clinical Chemistry Laboratory for their support during the study. We are especially grateful to Drs. Charles Metz and Ben Herman of the Department of Radiology, University of Chicago, 5841 S. Maryland Avenue, Chicago, IL 60637, for providing us with the LABROCl software.

\section{References}

1. Murata GH. Evaluating chest pain in the emergency department. [review] West J Med 1993; 59:61-8.

2. Lott JA, Stang JM. Serum enzymes and isoenzymes in the diagnosis and differential diagnosis of myocardial ischemia and necrosis. [review] Clin Chem 1980; 26:1241-50.

3. Lee TH, Goldman L. Serum enzymes assays in the diagnosis of acute myocardial infarction. Ann Int Med 1968; 105:22133.

4. Bernstein LH, Good IJ, Holtzman GI, Deaton ML, Babb J. Diagnosis of acute myocardial infarction from two measure-

ments of creatine kinase isoenzyme MB with use of nonparametric probability estimation. Clin Chem 1989; 35:444-7.

5. Collinson PO, Rosalki SB, Flather M, Wolman R, Evans T. Early diagnosis of myocardial infarction by timed sequential enzyme measurements. Ann Clin Biochem 1988; 25:376-82.

6. Leung FY, Griffith AP, Jablonsky G, Henderson AR. Comparison of the diagnostic utility of time serial (slope) creatine kinase measurements with conventional serum tests in the early diagnosis of myocardial infarction. Ann Clin Biochem 1991; 28:78-82. 
7. Jaffe AS. More rapid biochemical diagnosis of myocardial infarction: Necessary? Prudent? Cost effective? Clin Chem 1993; 39:1567-9.

8. Puleo PR, Guadagno PA, Roberts R, Scheel MV, Marian AJ, Churchill D., et al. Early diagnosis of acute myocardial infarction based on assay for subforms of creatine kinase-MB. Circulation 1990; 82:759-64.

9. Zweig MH, Campbell G. Receiver-operating characteristic (ROC) plots: a fundamental evaluation tool in clinical medicine. Clin Chem 1993; 39:561-77.

10. Collinson PO, Moseley D, Stubbs PJ, Carter DG. Troponin T for the differential diagnosis of ischaemic myocardial damage. Ann Clin Biochem 1993; 30:11-6.
11. Collinson PO, Stubbs PJ. The prognostic value of serum troponin $T$ in unstable angina. $N$ Engl $J$ Med 1992; 327:1760-1.

Prof. Dr. John A. Lott

Dept. Pathology

Starling Loving Hall M-368

The Ohio State University Medical Center

Columbus, $\mathrm{OH} 43210-1240$

USA 